\title{
Duration of weaning-oestrus interval and prolificacy of sows : statistical study of the influence of various reproductive parameters
}

\author{
M. ÉTIENNE et P. H. DUÉE \\ Station de Recherches sur l'Élevage des Porcs, I. N. R. A., C. N.R. Z., \\ 78350 Jouy en Josas
}

Existence of statistical relationships between some criteria of productivity in sows (weaningconception interval, prolificacy) and various parameters measured during the previous reproductive cycle (weight variation and feed intake of dams and piglets) was investigated in 183 Large White sows. These relationships were estimated from the calculation of linear correlation coefficients and by establishment of multiple linear correlations. The female population studied was characterized by a high proportion of primiparous animals (43 p. I0O) and small weight gains during the reproductive cycle $(+\mathrm{I} 6.7 \mathrm{~kg})$.

The duration of the weaning-oestrus interval and weaning-conception interval were negatively correlated with the litter order ( $-0.2 \mathrm{II}$ and -0.188 , respectively for the two intervals) and the weight of the sows at weaning ( -0.178 and -- 0.165$)$. However, the share of the variance explained by these two parameters was restricted $\left(\mathrm{R}^{2}=0.05\right)$. This was also the case for prolificacy which was only significantly correlated with the duration of weaning-oestrus or weaningconception intervals $(r=0.164)$ and the variation in the weight of the sows between weaning and mating $(r=0.188)$. This weight variation was related to the weight of the sows at weaning $(r=-0.455)$ and to the duration of the weaning-oestrus interval $(r=-0.594)$, these two factors accounting for $4^{8} \mathrm{p}$. Ioo of the variation. Although this study has been made on animals exhibiting a low productivity, it demonstrates the existence of relationships between changes in the weight of the sows and their further performances.

\section{Application of weaning at 12 days in pig herds. Comparative results of the productivity of sows over a period of three years}

\author{
A. AUMAITRE et J. LE PAN \\ Station de Recherches sur l'Élcvage des Porcs, I. N. R. A., C. N. R.Z., \\ r8350 Jouy en Josas
}

One thousand three hundred and seventy seven litters from 5 herds controlled in the western part of France between January 1972 and October 1974 were weaned by pairs, on an average after either 13.3 days of suckling (7oo litters) or after 38.3 days (677 litters). The reproductive 